\title{
Pharmacy Education Conference 2020 Manchester, United Kingdom
}

\section{LEARNING FOR SUCCESS}

\author{
M.Pharm. students perceptions of assessment and \\ feedback \\ I. Ahmed, N. Aghmasjed, G. Cutting, E. O'Hagan, E. Sutton, A. \\ Windle, R. Ledder, H. Parmar* \\ University of Manchester, United Kingdom \\ *Corresponding Author: harsha.parmar@manchester.ac.uk
}

Background: Assessment and feedback are integral throughout the education process. In the UK, schools of pharmacy (SOPs) are responsible for ensuring and demonstrating that their M.Pharm. graduates meet the General Pharmaceutical Council's (GPhC) learning outcomes. This is largely achieved through utilising a wide range of assessment and feedback techniques (GPhC, 2011). There is dissatisfaction amongst students with these processes (National Student Survey, 2011) and a 'gulf' is said to exist between staff and student perception on feedback in particular (Carless, 2006).

Aim: To determine the student perception of efficacy and utility of feedback and assessment strategies on the University of Manchester (UoM) M.Pharm.

Method: An anonymous survey was distributed to all UoM M.Pharm. students $(n=600)$. Respondents were asked to (dis)agree with 39 statements relating to assessment and feedback using a 5-point likert scale ( $5=$ strongly agree; $1=$ strongly disagree), preference types of assessment/feedback and respond to free text questions. An independent samples $t$-test was conducted to compare perceived satisfaction with feedback by year-group.

Results: Response rate was 69\%; 415 responses collected; $25 \%$ male $(n=104)$ and $73 \%$ female respondents $(n=311)$. Mean satisfaction with assessment (1-dissatisfied, 10-satisfied), was 6.3. Students were less satisfied with feedback than with assessment; themes included lack of individualised feedback (97\% [ $n=403$ ] respondents preferred individualised vs generalised feedback). Final-year students were significantly less satisfied with feedback ( $M=5.48$ vs $M=6.32$ for all other years, $p<0.001)$. There was significant difference between agreement that feedback has improved performance $(F(3,396)=$
3.678, $p=0.012)$. Tukey post-hoc tests revealed that final-year students $(1.08 \pm 0.27)$ were statistically more likely to agree with this statement than third-years $(1.01 \pm 0.09), p<0.016$.

Conclusion: Assessment and feedback are both essential parts of learning on the M.Pharm. degree. Since students in their final year are significantly more dissatisfied with their feedback, mirroring the findings in the wider literature (National Student Survey, 2011), effort should be directed at improving individualised feedback for this year group with an aim to improving attainment and satisfaction. Further analysis is needed to determine specific changes required to improve utility, of both assessment and feedback.

\section{References}

General Pharmaceutical Council. (2011). Future pharmacists: Standards for the initial education and training of pharmacists. Available at: https://www. pharmacyregulation.org/sites/default/files/document/future pharmacists standards for the initial education and training of pharmacists.pdf

National Student Survey. (2011). Findings and Trends 2006 to 2010. Higher Education Funding Council for England (online). Available at https:// dera.ioe.ac.uk/2560/1/11 11.pdf

Carless, D. (2006). Differing perceptions in the feedback process. Studies in Higher Education, 31(2), 219-33 The rise of veganism: are future pharmacists
prepared?

L.-A. Hanna*, F. Carabine, M. Hall

Queen's University Belfast, United Kingdom

*Corresponding Author:I.hanna@qub.ac.uk

Background: A key role for pharmacists is health promotion, including advising people about nutrition (General Pharmaceutical Council, 2011). Given the increasing prevalence of veganism, pharmacists should be cognizant of issues that may arise from people adopting this practice: they may be required to check product excipients, formulation processes, and establish whether alternatives exist. 
Aims: To investigate future pharmacists' knowledge of, and views on, veganism and ascertain whether various parameters (gender and being vegan) affected responses.

Method: Following ethical approval, final year Master of Pharmacy (M.Pharm.) students at Queen's University Belfast were invited to participate in this voluntary study. Data were collected via a pre-piloted questionnaire (distributed at a compulsory class in 2019) developed using the wider literature (The Vegan Society, 2019). Only non-identifiable data were requested with questions being largely closed-question type. Numerically coded responses were entered into Microsoft Excel and SPSS (Version 22). Students were scored on knowledge (22 statements; true/false answers). Other analysis about views largely took the form of descriptive statistics. Mann Whitney UTest was employed for inferential statistical analysis with significance set at $p<0.05$ a priori.

Results: The response rate was $91.09 \%$ (92/101); only one reported being vegan which limited analysis. Mean knowledge score was 16.59 ( \pm 2.43$)$. Only 36.96\% (34/92) reported feeling confident discussing veganism with patients or other healthcare professionals and $40.22 \%$ (37/92) deemed they could establish whether a medical product is vegan-friendly. A minority $[4.35 \%$ (4/92)] considered they had received adequate training on veganism on the degree programme. Males were more likely than females to consider that vegans are too forceful with their beliefs [74.19\% (23/31) versus 51.67\% (31/60); $p=0.043)$.

Conclusion: Useful baseline data about veganism has been obtained (albeit from a small sample and at one institution only). A gap has been exposed in the education provision which should be addressed in the next academic year.

\section{References}

General Pharmaceutical Council. (2011). Future pharmacists: Standards for the initial education and training of pharmacists (online). Available at: https://www.pharmacyregulation.org/sites/default/files/document/ gphc future pharmacists may 2011.pdf

The Vegan Society (2019). Nutrition and health (online). Available from: https://www.vegansociety.com/

\section{A study to investigate how undergraduate pharmacy students develop integrated knowledge about pain}

\author{
H. Nazar*, A. Patel, E. Manton, A. Husband \\ Newcastle University, United Kingdom \\ *Corresponding Author: hamde.nazar@newcastle.ac.uk
}

Background: Pain and its management, requires complex understanding of human biological, chemical and practical concepts. Undergraduate students from a Masters of Pharmacy programme in one School of Pharmacy in England, are taught this topic within educational activities aligned to the interdisciplinary level of integration (Harden, 2000). This study aims to explore if and how these students develop integrated knowledge as they experience the curriculum on pain.

Method: Undergraduate students (Year 3, n=65) were invited to participate in a set of longitudinal activities during the five-week teaching course on pain. Consenting students produced weekly concept maps to illustrate what they knew and understood about pain and its management. Each participant concept map was analysed for cognitive progression using a framework assessing for: organisation, integration, and concepts. Within weekly interviews, students described what they aimed to illustrate in their concept map. The interviews were transcribed verbatim and transcriptions qualitatively analysed using thematic coding to identify the common themes.

Results: Ten students agreed to participate, contributing 50 concept maps and 50 interviews. As the study progressed, the concept maps demonstrated increased complexity, organisation, integration and knowledge. The singular hierarchies decreased for the majority of participants $(n=8)$, also confirming increased knowledge integration. Students illustrated concepts across all areas of clinical and pharmacy practice, and the pharmaceutical sciences, apart from microbiology, despite being taught this within the context of pain. During the interviews, students reported an integrated approach to learning and over the five weeks, were populating a scaffold of interlinking concepts, e.g. pathophysiology, pharmacology, etc. with more detailed knowledge of pain.

Conclusion: Undergraduate students learning about pain within an interdisciplinary integrated curriculum appear to have developed a road map for integrated thinking before having being taught all the material. Further work is required to investigate if the spiral nature of the programme facilitates the development of this cognitive network.

\section{References}

Harden, R.M. (2000). The integration ladder: a tool for curriculum planning and evaluation. Medical Education, 34(7), 551-557

\section{A study to investigate undergraduate pharmacy students' experience of an integrated curriculum}

H.Nazar*, A.Khan, A.Husband

Newcastle University, United Kingdom

*Corresponding Author: hamde.nazar@newcastle.ac.uk

Background: Curriculum integration in pharmacy undergraduate programmes is being increasingly adopted. The extent and form of integration between and within programmes varies across the steps of Harden's integration ladder (Harden, 2000). This study aims to investigate how undergraduate students experience an integrated Master of Pharmacy (M.Pharm.) programme at one School of Pharmacy in England. 
Method: The M.Pharm. programme is constructed as an integrated, spiral curriculum, generally achieving the interdisciplinary step of the integration ladder (Husband, 2014). Undergraduate students in Stages 1 to 3 were invited to participate in exploratory focus groups to investigate their learning experience. Modified grounded theory provided the framework for data collection and analysis (Glaser, 1967). Subsequent explanatory semi-structured interviews were undertaken with individual students across these cohorts to explore the themes derived from focus groups. Focus group discussions and interviews were audio-recorded with written consent, transcribed verbatim and thematically analysed.

Results: Twelve students participated in two focus groups and a further nine in semi-structured interviews. Four themes identified from the thematic analysis included: preparing for the role of a pharmacist, learning strategies in an integrated programme; adjusting to an integrated curriculum, and becoming an 'integrative thinker'. Overall, students enjoyed integrated teaching, explaining that it allows development of crucial problem-solving skills and knowledge and competencies required for the role of a pharmacist. Students in the latter stages of the programme, described the difficulties in adjusting to an integrated curriculum during the first year, but suggest integration came 'naturally' by the third year, after their experience of teaching and learning in the second year.

Conclusion: Students require time to adjust to the less fragmented teaching characterised by an integrated curriculum. However, there is an appreciation that the integrated educational activities facilitate the development of key cognitive skills that will prove valuable in the provision of patient care.

\section{References}

Harden, RM. (2000). The integration ladder: a tool for curriculum planning and evaluation. Medical Education, 34(7), 551-7

Husband, A.K..., Todd, A., \& Fulton, J. (2014). Integrating science and practice in pharmacy curricula. American Journal of Pharmaceutical Education, 78(3), 63. https://doi.org/10.5688/aipe78363

Glaser, B.G., \& Strauss, A.L. (1967). The discovery of grounded theory: strategies for qualitative research. London: Weidenfeld and Nicolson

\section{Developing pharmacy students as reflective thinkers for the evolving field of pharmacy: an insight into student reflective approach}

\author{
H.Nazar*, A.Husband \\ Newcastle University, United Kingdom \\ *Corresponding Author: hamde.nazar@newcastle.ac.uk
}

Background: Reflection is important in a learning experience: at the start in anticipation, during the experience towards managing the array of information and provoked thoughts and feelings, and following the experience during a phase of debriefing and consolidation (Boud, 2013). The purpose of reflection serves two aims: first to develop learning that is focused on conceptual knowledge and understanding, and second to improve professional practice (Mamede, 2004).

This study focuses on one programme approach, where students experience a series of seminars across the four undergraduate years to develop their understanding and skills in reflective practice and its articulation. The aim is to explore the student learning and development of reflection through analysing accounts submitted in their final year of the programme.

Method: Stage (Year) 4 students engage in a reflection conference presenting a reflective account of a 'Significant Learning Event' or upon their journey 'From Student to Professional'. Conference abstracts submitted in 2017-18 $(n=45)$ and 2018-19 $(n=62)$ were retrieved with consent. Content analysis was employed to systematically and objectively explore the student-reported experience of learning and development.

Results: One hundred and seven abstracts were analysed. Students reflected mainly upon experiences across extra- and co-curricular activities and related some of the six types of Fink's significant learning (Fink, 2003). Notably, very few students related stories about learning foundational knowledge, with all other forms of significant learning, especially human dimension, caring and learning to learn, very highly referenced.

Conclusion: Students shared stories about skills, attributes and emotions experienced across a range of contexts. The commonality was often the involvement of patients or the public, and students' self-derived appreciation of those gained, experienced or observed skills, attributes and emotions. Students were demonstrating purposeful, deliberate introspection and metacognition in their abstracts. These skills are fundamental to support transformative learning, whereby students have the ability to self-regulate and critique their frames of reference with autonomy and flexibility better preparing them for lifelong learning within the profession.

\section{References}

Boud, D., Keogh, R., \& Walker, D. (2013). Reflection: Turning experience into learning. Routledge

Fink, L.D. (2003). Creating significant learning experiences: An integrated approach to designing college courses. San Francisco: Jossey-Bass.

Mamede, S., \& Schmidt, H.G. (2004). The structure of reflective practice in medicine. Medical Education, 38(12), 1302-8. https://doi.org/10.1111/i. $\underline{1365-2929.2004 .01917 . x}$

\section{A study to investigate the factors influencing professional engagement of undergraduate students undertaking a capstone research module}

A. Akindele*, A. Husband, H. Nazar

Newcastle University, United Kingdom

*Corresponding Author: hamde.nazar@newcastle.ac.uk 
Background: Professional engagement has been defined as an energising state of mind characterised by vigour, dedication and focus. It drives an individual to go beyond primary expectations in their career and make an impact, or advocate for that profession (Aronson, 2012). Professional engagement as an undergraduate, has been suggested to positively impact students' capacity and willingness to enhance the profession later in their careers. This research aims to investigate if and how the capstone research project module, mandatory for Stage (Year) 4 students at a school of pharmacy, impacts on professional engagement.

Method: A mixed methods approach included the employment of a validated tool, the 'Student Pharmacist Inventory for Professional Engagement' (S-PIPE), electronically distributed to the cohort $(n=43)$, with follow-up semi-structured interviews employing an adapted grounded theory approach (Strauss, 1997), conducted at baseline and after the ten-week research module. Interviews were conducted by students from the same cohort in an attempt to avoid perception of coercion and bias from social desirability. Quantitative data that was pseudoanonymised to allow for matching, was analysed using descriptive statistics and investigated for difference using $t$-tests and paired $t$-tests. Pseudo-anonymised survey data was not linked to qualitative data. Transcribed interviews were inductively, thematically analysed. The study received favourable institutional ethical approval.

Results: The response rate was $76.7 \%(n=33)$ and $48.8 \%(n=21)$ at baseline and at ten-weeks respectively. There was no significant difference of S-PIPE scores across the survey domains, nor across the matched responses. Thematic analysis of the ten student interviews however indicated an increase in passion, connectedness and meaningful experience after engagement in the research module. Students described activities that influenced their professional engagement, impact of the research module, the impact of others, and other factors to improve professional engagement

Conclusion: The validated S-PIPE tool has not captured change in professional engagement across this short time period nor across the educational intervention. However, students report that experience of a dedicated module where they are immersed in the planning, management and write up of a research project does impact their professional engagement, and students provide further insight of influential factors, positive and negative.

\section{References}

Aronson, B.D., Janke, K.K., \& Traynor, A.P. (2012.) Investigating student pharmacist perceptions of professional engagement using a modified Delphi process. American Journal of Pharmaceutical Education, 76(7). https://doi.org/10.5688/ajpe767125

Strauss, A., \& Corbin, J. (1997). Grounded theory in practice. Sage. Thousand Oaks CA.
An evaluation of a team-based learning in Reading School of Pharmacy alumni study day

\author{
K. Ridout \\ University of Reading, United Kingdom \\ Corresponding Author: k.ridout@reading.ac.uk
}

Background: The University of Reading are committed to providing alumni student support through their virtual learning environment and a mock pre-registration exam. In April 2019, they developed a team-based learning (TBL) event aligned to the General Pharmaceutical Council (GPhC) assessment high weighing therapeutic areas and calculations. TBL has shown to promote high academic achievement (Bleske et al., 2016).

Aim: To explore students' experience of a newly developed TBL event.

Method: Fifty alumni students attended the TBL. Attendees were asked to complete online feedback afterwards. This included six questions on: exam helpfulness (score 0-100); if they would recommend to peers (yes/no); qualitative feedback on areas liked and areas to be improved; feedback on future study day topics; and desire for an exam preparation webinar.

Results: Seventy percent $(n=35)$ provided feedback. The average score for helpfulness in exam preparation was $82(S D=22)$, and a range of 16-100. Ninety-one percent would recommend the TBL event to their peers. Moderate positive correlation was found between helpfulness score and positive recommendation to peers $\left(p=0.002,=R_{s}=0.5249\right)$. Positive themes included: focus on high weighting therapeutic areas, use of GPhC style exam Q\&A sheets, and use of TBL. The themes on improvement included; wish to discuss all of the questions rather than just the more difficult ones, some questions considered too simple, and more time to be spent on each topic.

Conclusion: The majority of students had a positive learning experience. The data collected from our initial TBL has helped develop our understanding of the types of learning the students' value and how we can best support them. In 2020, we have expanded alumni support to two TBL events allowing more time to be spent on each high-weighing topic. These findings and the subsequent exam results may provide further context on the most effective pedagogy for UK pharmacy students.

\section{References}

Bleske, B., Remington, T., Wells, T., Klein, K., Guthrie, S., Tingen, J., Marshall, V., \& Dorsch, M., 2016. A Randomized Crossover Comparison Of Team-Based Learning And Lecture Format On Learning Outcomes. American Journal of Pharmaceutical Education, 8(7), 120. https://doi.org/ $\underline{10.5688 / a j p e 807120}$ 
Establishing the roles undertaken and clinical skills needed by general practice-based pharmacists: A web-based survey

B. Girvin*, U. Akpan, N. Hampson, H. Middleton, L. Sims, H. Barry

School of Pharmacy, Queen's University Belfast, United Kingdom

*Corresponding Author: $\underline{\text { b.girvin@qub.ac.uk }}$

Keywords: Clinical Skills, Independent Prescribing, Practicebased Pharmacists, Primary Care

Background: 'Clinical skills' refers to clinical examination and procedural skills. As more pharmacists work in primary care and take on greater patient-facing roles, it has become a priority to ensure they have the necessary clinical skills (Sims, 2017). Evidence is emerging that practice-based pharmacists (PBPs) do not feel confident regarding their clinical skills (General Pharmaceutical Council, 2016; Girvin 2018).

Aim: Identify the roles undertaken by PBPs, clinical skills needed to undertake their role, and their views on provision of clinical skills training by independent prescribing (IP) courses.

Method: Following ethical approval, a web-based survey was distributed to PBPs within two Commissioning Support Units (Greater Manchester, Midlands \& Lancashire). Primary Care Pharmacist Association members were also invited to complete the questionnaire via Twitter. It comprised four sections collecting sociodemographic data about respondents and their practices, establishing roles undertaken by PBPs, and the clinical skills required for their role. The skills comprised those listed in a pharmacy postgraduate assessment record/learning tool (CPPE, 2018) with additional skills informed by the literature. Responses were coded, entered into SPSS v.26, and analysed descriptively.

Results: One hundred PBPs responded; 56\% ( $n=56$ ) had worked as a PBP for $\leq 2$ years and $66 \%(n=66)$ held an IP qualification. The most common roles undertaken were 'responding to queries about medicines' (89\%, $\mathrm{n}=89$ ), 'handling hospital discharge information/medicines reconciliation' (83\%, $n=83$ ), and 'undertaking face-to-face medication reviews' (83\%, $n=83$ ). Clinical skills rated most relevant by respondents were heart rate, blood pressure, and height/weight/BMI (Table I). A large proportion of those who had undergone IP training $(47 \%, n=31)$ showed ambivalence or disagreement with the statement 'the IP course provided me with adequate training regarding the necessary clinical skills to work in primary care'.

Conclusion: The results of this study should inform the creation of a core set of clinical skills required for pharmacists to work in general practice.

\section{References}

CPPE [Centre for Pharmacy Postgraduate Education]. (2018) Clinical and Procedural Skills, a CPPE assessment record. Available at: https:// www.cppe.ac.uk
General Pharmaceutical Council. (2016) Prescribers Survey Report. 1-54. Available at: https://www.pharmacyregulation.org/sites/default/files/ gphc_prescribers survey report.pdf

Girvin, B., Wilson, D. (2018) Clinical skills training for pharmacists in general practice. Prescriber, 29 (11), 19-25. https://doi.org/10.1002/psb.1724

Sims, L., Campbell, J. (2017) Ills, pills, and skills: Developing the clinical skills of pharmacists in general practice. British Journal of General Practice, 67(662), 417-418. https://doi.org/10.3399/bigp17X692453

Table I: Respondents' mean rating of clinical skills (rated on a scale of 1 to 10 )

\begin{tabular}{|c|c|}
\hline Clinical skill & $\begin{array}{l}\text { Mean rating } \\
\text { ( } \pm \text { Standard Deviation) }\end{array}$ \\
\hline *Blood pressure (manual) & $9.08( \pm 2.05)$ \\
\hline *Blood pressure (automated) & $8.83( \pm 2.07)$ \\
\hline *Heart rate (radial pulse) & $8.80( \pm 2.13)$ \\
\hline${ }^{*}$ Height, weight and body mass index & $8.77( \pm 2.23)$ \\
\hline $\begin{array}{l}\text { *Respiratory function: peak expiratory flow } \\
\text { rate }\end{array}$ & $8.28( \pm 2.52)$ \\
\hline *Peripheral oxygen saturation & $8.24( \pm 2.80)$ \\
\hline *Temperature & $8.17( \pm 2.80)$ \\
\hline${ }^{*}$ Respiratory rate & $8.11( \pm 2.66)$ \\
\hline *Blood glucose & $7.47( \pm 2.84)$ \\
\hline *Urinalysis & $7.24( \pm 3.03)$ \\
\hline Spirometry testing and interpreting & $7.23( \pm 3.03)$ \\
\hline Examination of the leg for a diabetic review & $6.99( \pm 3.03)$ \\
\hline *Respiratory examination & $6.96( \pm 3.30)$ \\
\hline${ }^{*}$ Cardiovascular system examination & $6.25( \pm 3.16)$ \\
\hline *Ear examination & $6.07( \pm 3.39)$ \\
\hline *Throat examination & $5.97( \pm 3.36)$ \\
\hline Dorsalis pedis (foot) pulse & $5.97( \pm 3.48)$ \\
\hline Posterior tibial (foot) pulse & $5.74( \pm 3.58)$ \\
\hline $\begin{array}{l}\text { Examination of the lymph nodes of the head } \\
\text { and neck }\end{array}$ & $5.66( \pm 3.41)$ \\
\hline Examination of the leg (general) & $5.65( \pm 3.04)$ \\
\hline Brachial pulse & $5.64( \pm 3.19)$ \\
\hline Joint examination & $5.31( \pm 3.25)$ \\
\hline Gastrointestinal examination & $5.27( \pm 3.52)$ \\
\hline Carotid pulse & $5.20( \pm 3.02)$ \\
\hline Examination of the eyes & $5.14( \pm 3.44)$ \\
\hline Nervous system (sensory) & $5.05( \pm 3.05)$ \\
\hline Examination of the sinuses & $4.90( \pm 3.31)$ \\
\hline Nervous system (motor) & $4.76( \pm 3.08)$ \\
\hline Nervous system (cranial) & $4.39( \pm 3.03)$ \\
\hline Popliteal (behind knee) pulse & $4.18( \pm 3.04)$ \\
\hline Phlebotomy & $4.14( \pm 2.96)$ \\
\hline Femoral (groin) pulse & $4.08( \pm 3.03)$ \\
\hline
\end{tabular}

*Denotes skills included within Clinical and Procedural Skills, a CPPE assessment record (CPPE, 2018). 
An evaluation of the pharmacist independent prescribing programme at Queen's University Belfast using semi-structured telephone interviews

B. Girvin*, E. Cassidy, S. Haughey, R. O’Hare, M.-C. Kearney

School of Pharmacy, Queen's University Belfast, United Kingdom

*Corresponding Author: $\underline{\text { b.girvin@qub.ac.uk }}$

Keywords: Independent Prescribing, Distance Learning, Course Evaluation

Background: The School of Pharmacy at Queen's University Belfast (QUB) provides an independent prescribing (IP) programme for pharmacists living in England, Scotland and Wales. Studies evaluating prescribing programmes are sparse (George et al., 2007; Cooper et al., 2008).

Aim: To evaluate the IP programme by interviewing pharmacists who completed it in 2018.

Method: Following ethical approval, all seventeen pharmacists who completed the IP programme in 2018 were invited to participate in semi-structured telephone interviews. Their views were obtained about teaching methods, course content, support and perceived preparedness for practice. Interviews were digitally recorded, transcribed verbatim, and analysed thematically.

Results: Nine pharmacists took part in the study during February 2019. Five themes emerged as shown in Table I with sample quotations. Pharmacists thought that course length (nine months), structure (six modules including a one week residential) and distance learning methods used were appropriate. They thought they were well supported but medical mentors could have been supported more. Recommendations included more teaching on history-taking and abnormal findings on examination.

Conclusion: This study provided valuable feedback, which when considered alongside the new standards for IP education, (GPhC, 2019) has informed the redesign of the IP programme at QUB.

\section{References}

Cooper, RJ., Lymn, J., Anderson, C., Avery, A., Bissell, P., Guillaume L., et al. (2008). Learning to prescribe - pharmacists' experiences of supplementary prescribing training in England. BMC Medical Education, 8(1), 1-8. https:// doi.org/10.1186/1472-6920-8-57

GPhC [General Pharmaceutical Council]. (2019) Standards for the education and training of pharmacist independent prescribers. Available at: https://www.pharmacyregulation.org/sites/default/files/document/ standards-for-the-education-and-training-of-pharmacist-independentprescribers-january-19.pdf

George, J., McCaig, D., Bond, C.M., Cunningham, I.S., Diack, H.L., \& Stewart, D.C. (2007). Benefits and challenges of prescribing training and implementation: Perceptions and early experiences of RPSGB prescribers. International Journal of Pharmacy Practice, 15(1), 23-30. https://doi.org/ 10.1211/ijpp.15.1.0005
Table I: Themes and sample quotations from the IP telephone interviews

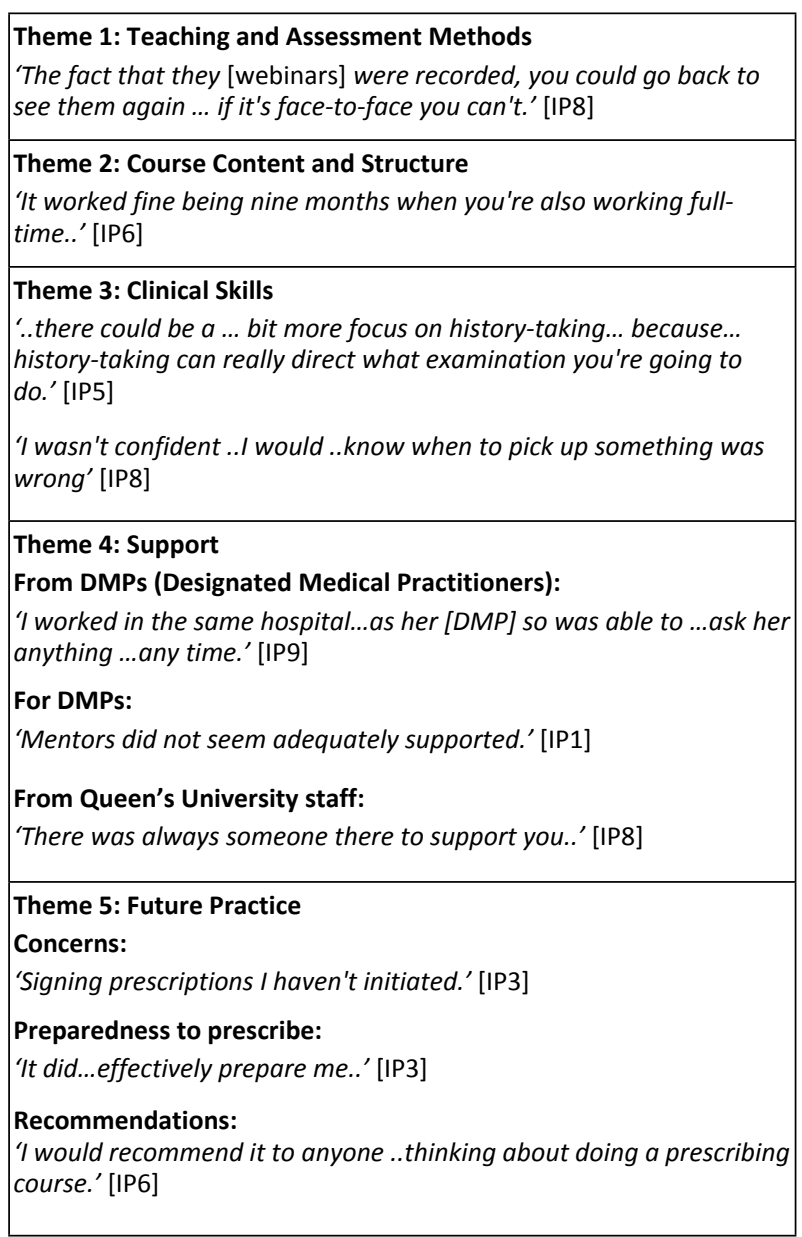

\section{Investigating pharmacy student engagement}

C. Langran*, N. Shafaghmotlagh

University of Reading, United Kingdom

*Corresponding Author: c.a.langran@reading.ac.uk

Background: Student engagement is defined as students' devotion to educational activities, leading to positive experiences and enhanced learning outcomes (Trowler, 2010). Non-engagement may cause voluntary withdrawal or dropouts. Eight percent of UK students leave university during their first year and $37-42 \%$ consider leaving (HEA, 2012).

Aim: This study aimed to explore pharmacy students' perception of and influences on engagement.

Method: Ethics approval was granted. Eleven undergraduate pharmacy students volunteered (Part $1 \mathrm{n}=2$; Part $2 \mathrm{n=1}$; Part 3 $n-3$; Part $4 n=5$ ). One-to-one interviews were led by a peer pharmacy student and lasted 45-60 minutes. The interview guide and priori codes for deductive analysis were based upon the seven engagement scales shown in Figure $A$. 


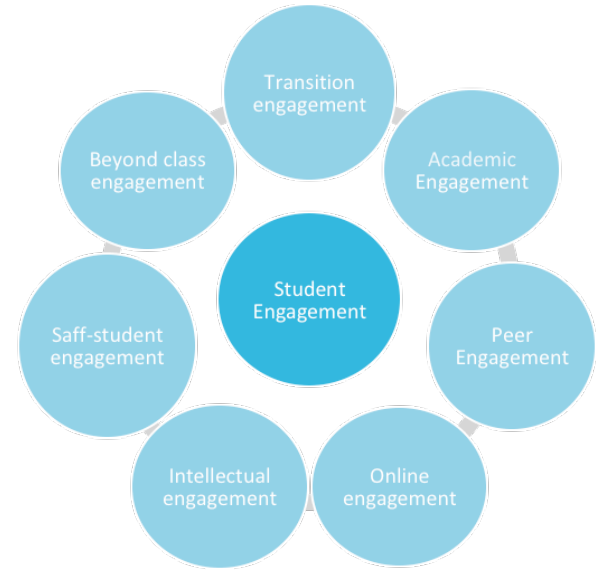

Figure A: Theoretical framework for student engagement adapted from Krause \& Coates (2008)

Results: Comparable responses from participants were found within the following themes:

1. Transition engagement: students felt welcomed during their first weeks and appreciated having a pharmacy student mentor. Students struggled with the increased complexity and workload, and the new autonomy on whether to attend or not.

2. Academic engagement: all students expressed a strong motivation to study pharmacy.

3. Peer: students described positive and negative influences from friends. There was a dislike for group work.

4. Staff-student engagement: most staff members were described as approachable, knowledgeable and helpful.

5. Intellectual engagement: students enjoyed varied teaching styles, and found placements and Inter-professional learning most relevant and interesting.

6. Online engagement: students regularly accessed the virtual learning environment, and discussed the distractions of social media and the internet.

7. Beyond-class engagement: students reported enjoying a range of university facilities and events. However, these were often restricted by their time spent in class and studying.

Conclusion: This qualitative study gives a valuable insight into intrinsic and extrinsic influences on students' engagement. Measures can be taken to improve the social and academic systems to enhance and support student engagement.

\section{References}

HEA [Higher Education Academy]. (2012). Building student engagement and belonging in Higher Education at a time of change: final report from the What Works? Student Retention and Success Programme. Available at: https://www.advance-he.ac.uk/knowledge-hub/building-studentengagement-and-belonging-higher-education-time-change-final-report

Krause, K.L., \& Coates, H. (2008). Students' engagement in first-year University. Assessment \& Evaluation in Higher Education, 33(5), 493-505. https://doi.org/10.1080/02602930701698892

Trowler, V. (2010). Student engagement literature review. The Higher Education Academy. 11(1), 1-15. https://www.heacademy.ac.uk/system/ files/StudentEngagementLiteratureReview 1.pdf

\section{Peer-led mock exams: What motivates students to support the learning of others?}

\author{
J. Hall*, E. Collinson, S. Govind, H. Mann, J. Murphy. \\ University of Manchester, United Kingdom \\ *Corresponding Author: Jason.Hall@manchester.ac.uk
}

Background: Students can feel unprepared for assessments because the assessment format in university can differ from school (Wilson et al., 2016). In addition, students have had access to many more past/sample papers at school compared to university.

One approach to addressing this involved medical students volunteering to write questions and run workshops for junior students (Clunes \& Clunes 2019). This model was adapted for a pilot workshop involving Year 4 project students writing mock exams which were reviewed by staff. Year 2 students attended the workshop to sit the mock exam and receive feedback on the correct/incorrect answers. The roll out of this pilot requires participation by future Year 4 students

Aim: This project aimed to explore the factors that motivate participation by Year 4 students.

Method: A survey was developed following a review of the project student's reflections after they ran the mock exam workshop. A hard copy of the survey was distributed to all Year 4 students during class time. The results were entered on a spreadsheet for analysis.

Results: There was a $76.9 \%$ responses rate $(n=110 / 143)$. Twentynine percent of Year 4 students were willing to write questions for mock exams and $45.3 \%$ were willing to run a mock exam/ feedback session.

\section{Table: Motivation to take part}

\begin{tabular}{l|c}
\hline $\begin{array}{l}\text { How likely are the following to motivate you to take part? } \\
\text { (1=very unlikely to } 5 \text { very likely) }\end{array}$ & Mean \\
\hline Being reimbursed for taking part in the sessions (e.g. f10/hr) & 4.63 \\
\hline Points towards the PLEDGE award & 2.95 \\
\hline Being able to write it on your CV & 3.36 \\
\hline $\begin{array}{l}\text { Opportunity to reflect and consolidate knowledge from earlier on in } \\
\text { the course }\end{array}$ & 3.27 \\
\hline Develop teaching skills to help me in my future career. & 3.38 \\
\hline Interacting with students in younger years & 2.72 \\
\hline $\begin{array}{l}\text { Satisfaction from helping younger students- a sense of reward } \\
\text { through knowing that you can make a difference }\end{array}$ & 3.25 \\
\hline Enhance leadership skills & 3.39 \\
\hline Improve my communication and interpersonal skills & 3.69 \\
\hline Being able to meet new people from different years of the MPharm & 2.91 \\
\hline
\end{tabular}

Conclusion: Engaging students to support other students has obvious attraction as it has potential to positively impact on student progression and satisfaction with relatively modest impact on staff workload. Student engagement is a pre-requisite and it is therefore important to be aware of factors that motivate participation. Payment is clearly a strong motivator but 
shouldn't be considered essential as it is not necessary to have all students participate. Low numbers of question writers will reduce the number of sessions that can be delivered. Initial setup funding to pay question writers would allow creation of a bank of questions for recycling in future years if the low number of writers was a barrier.

\section{References}

Clunes, L., \& Clunes, M. (2019) Peer-led MCQ Session, 13-14. Teaching Professor Conference, New Orleans. Available at: https://s30383.pcdn.co/ wp-content/uploads/pdfs/TPConpro19.pdf

Wilson, F., Child, S., \& Suto, I. (2016) Assessing the transition between school and university: Differences in assessment between $A$ level and university in English. Arts and Humanities in Higher Education, 16(2), 188-208. https://doi.org/10.1177/1474022216628302

\section{A qualitative exploration of the impact of a postgraduate quality improvement educational module on pharmacists' understanding and practice}

T. Ansong ${ }^{1 *}$, N. Gulzar ${ }^{1}$, A. Latif ${ }^{2}$

${ }^{1}$ Leicester School of Pharmacy, De Montfort University, United Kingdom ${ }^{2}$ School of Health Sciences, University of Nottingham, United Kingdom

*Corresponding Author: theo.ansong@dmu.ac.uk

Background: In line with the NHS plan to enhance safety and effectiveness of care (NHS, 2019) there is a drive to train and support healthcare professionals to adopt appropriate skills in quality improvement (QI) (Berg et al., 2016; Gleason et al., 2019). However, the evidence suggests that coherent approaches to postgraduate training or even organisational support are currently lacking (Ham, Berwick \& Dixon, 2016).

Aim: This study explores pharmacists' understanding of QI before and after completing a postgraduate learning module (course), and the subsequent impact on practice.

Method: Thirteen community pharmacists completed a 15credit postgraduate module (six months) on QI delivered by a higher education institution in Leicester. Four focus groups (two at the start [ $n=11]$, and two on completion $[n=5]$ ) were held during which participants' knowledge of Ql and extent of practical application following the learning were explored. Audio-recorded discussions were transcribed verbatim and analysed thematically for emergent themes.

Results: Pre-training: Pharmacists expressed positive views about learning new skills but had concerns about managing additional learning within their professional workload. Knowledge and application of QI concepts were reported to be lacking and ineffectual.

Post-training: Significant improvements in comprehension and application were apparent, and this extended to several areas of their practice. Overall, it was considered too early for participants to make an assessment on patient outcomes largely because of the time required to elicit comprehensive organisational support and embedding of proposed changes.

Conclusion: The findings suggest that pharmacists held positive views about learning new QI skills. After completing the module, their knowledge of QI had improved and its application in practice was more evident. In order to promote QI learning, concerns over professional workload may need to be addressed. Further research is needed to investigate whether pharmacist learning about QI translates into improved patient outcomes.

\section{References}

Bergh, A.M., Bac, M., Hugo, J. and Sandars, J., (2016). "Making a difference"Medical students' opportunities for transformational change in health care and learning through quality improvement projects. BMC Medical Education, 16(1), 171. https://doi.org/10.1186/s12909-016-0694-1

Gleason, K.T., VanGraafeiland, B., Commodore-Mensah, Y., Walrath, J., Immelt, S., Ray, E., \& Himmelfarb, C.R.D. (2019). The impact of an innovative curriculum to introduce patient safety and quality improvement content. BMC Medical Education, 19(1), 156. https://doi.org/10.1186/ s12909-019-1604-0

Ham, C., Berwick, D., \& Dixon, J., (2016). Improving quality in the English NHS. London: The King's Fund. Available at: https://www.kingsfund. org.uk/sites/default/files/field/field publication file/Improving-qualityKings-Fund-February-2016.pdf

NHS (2019). The NHS long term plan. Available at: https://www. longtermplan.nhs.uk

\section{Development of a conceptual model for the evaluation of inter-professional education}

\section{A. Manfrin*, A. Urmston, S. Seymour, A. Lunn \\ University of Central Lancashire, United Kingdom \\ *Corresponding Author: amanfrin@uclan.ac.uk}

Background: Inter-professional education (IPE) engages students from different healthcare professions for learning with, from and about each other to improve collaboration and quality of care (El-Awaisi et al., 2016). A systematic literature review suggested that studies on IPE report positive outcomes when teaching pre-clinical students from medicine and other healthcare professions (Vuurberg et al., 2019). This study is part of a two-year pedagogy research project, assessing the impact of IPE on medicine, nursing, pharmacy and physiotherapy students.

Aim: To develop a conceptual model for evaluating IPE using partial least squares structural equation modelling (PLS-SEM).

Method: Participant of the IPE session were invited to fill the RIPLS questionnaire (McFadyen et al., 2005) online, using Qualtrics.

The conceptual model tested 5 hypotheses. What was the impact of: - H1:positive attitude towards team-working on shared learning?

- H2: positive attitude towards team-working on team-working? - H3: negative attitude towards team-working on team-working? - $\mathrm{H} 4$ : negative attitude towards team-working on shared learning?

- H5: team-working on shared learning? 
The analysis was conducted using SmartPLS3 following the procedure suggested by Sarstedt et al. (2016). The study received ethics approval (Ref. HEALTH 0029).

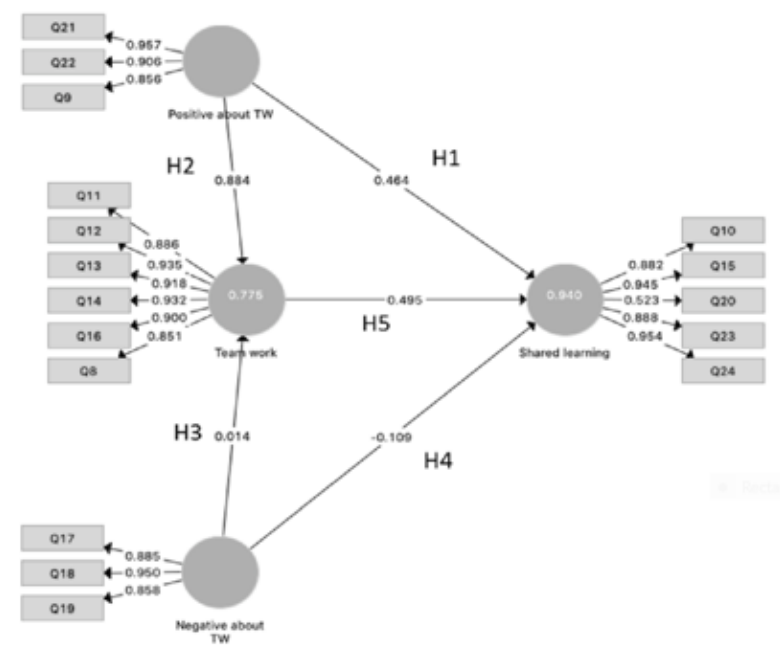

\section{Figure A: Structural model for interprofessional education}

$H=$ hypothesis. The direction of the arrows between the blue circles represents the hypotheses. The numbers overlapping the arrows between the blue circles are the path coefficients. The numbers between the blue circles and the yellow boxes are the loading coefficients. The numbers inside the blue circles are the coefficients of determination (R2). Qs (e.g. Q19) represent the items of the RIPLS questionnaire used for building the model.

Results: Thirty-four students attended the IPE session: 20 from pharmacy, 7 medicine, 4 nursing, 3 physiotherapy. Fourteen students were in $2^{\text {nd }}$ year, 10 in $3^{\text {rd }}, 8$ in $5^{\text {th }}, 2$ in $1^{\text {st }}$. Four path coefficients in the structural model were positive, one negative $(\mathrm{H} 1: \beta=0.464, \quad p<0.001 ; \mathrm{H} 2: \beta=0.884, \quad p<0.002 ; \mathrm{H} 3: \beta=0.014$, $p<0.963$; H4: $\beta=-0.109, p=0.300 ; \mathrm{H} 5: \beta=0.495, p<0.001$ ) (Figure $1)$. The model presented substantial explanatory power for shared learning $\left(R^{2}=0.940, p<0.001\right)$ and team working $\left(R^{2}=0.775, p<0.001\right)$; it did not fully achieve discriminant validity but showed a good fit (SRMR=0.083).

Conclusion: The study represents one of the first attempt to develop a conceptual model using PLS-SEM to evaluate an IPE session; the limitation of the model is the small sample size.

\section{References}

El-Awaisi, A., Anderson, E., Barr, H., Wilby, K., Wilbur, K. and Bainbridge, L., 2016. Important steps for introducing interprofessional education into health professional education. Journal of Taibah University Medical Sciences, 11(6), 546-551. https://doi.org/10.1016/i.jtumed.2016.09.004

McFadyen, A., Webster, V., Strachan, K., Figgins, E., Brown, H., \& Mckechnie, J. (2005). The Readiness for interprofessional learning scale: A possible more stable sub-scale model for the original version of RIPLS. Journal of Interprofessional Care, 19(6), 595-603. https://doi.org/ 10.1080/13561820500430157

Sarstedt, M., Hair, J., Ringle, C., Thiele, K., \& Gudergan, S. (2016). Estimation issues with PLS and CBSEM: Where the bias lies!. Journal of Business Research, 69(10), 3998-4010. https://doi.org/10.1016/i.jbusres. $\underline{2016.06 .007}$

Vuurberg, G., Vos, J., Christoph, L., \& de Vos, R. (2019). The effectiveness of interprofessional classroom-based education in medical curricula: $A$ systematic review. Journal of Interprofessional Education \& Practice, 15, 157-167. https://doi.org/10.1016/j.xjep.2019.01.007
What are postgraduate pharmacy diploma students' perceptions of team-based learning and how do these compare between groups and with those of undergraduate students?

\author{
R. Akhtar*, G. Quinn \\ University of Bradford, United Kingdom \\ *Corresponding Author: r.akhtar18@bradford.ac.uk
}

Background: Team-based learning (TBL) is an active and collaborative pedagogical approach (Mlchaelsen et al., 2002), which has recently been introduced on a postgraduate programmes at the University of Bradford. However, postgraduate (PG) students' perceptions and their preferences relating to this teaching method are poorly understood.

Aim: To assess the perceptions of PG students using the TBL student assessment instrument (TBL-SAI) (Mennenga, 2010).

Method: An online format of the TBL-SAI, a questionnaire, consisting of 33 items used to assess students' preference for TBL, was administered to PG students who were asked to voluntarily complete the tool during a study day. Statistical analysis using chisquared tests were performed to test for significant differences between the different subgroups: PG and undergraduate (UG) students; male/female students; summer/winter intake cohorts; first/second year students and students with/without TBL experience. Ethical approval was received on 4th November 2019. Raw data of TBL-SAl scores was obtained from a previous study at the university.

Results: Students' response rate was $70 \%(n=60)$. Total TBL-SAI scores and scores within each sub-scale showed the PG students had a preference for TBL over lectures. Sub-analysis between groups showed that a significant difference between UG and PG views, with UG showing a stronger preference foe TBL $(p=0.002)$. Those with prior experience of TBL were also more likely to prefer it to lectures $(p=0.03)$. There was no statistical difference between genders, cohorts or year groups.

Conclusion: Overall PG students preferred TBL to lectures, but less so than UG. Differing learning styles between groups of students and individuals may influence TBL preference (Gardner \& Korth, 1998; Shukr et al., 2013). Obtaining further qualitative data would help to understand PG students' motivation for preparation for TBL and also their learning styles. In the meantime, providing PG students the opportunity to experience both lectures and TBL may help to achieve balance in teaching methods.

\section{References}

Gardner, B.S., \& Kprth S.J. (1998). A framework for learning to work in teams. Journal of Education for Business, 74(1), 28-33. https://doi.org/ $\underline{10.1080 / 08832329809601657}$

Mennenga, H.A. (2010). Team-Based Learning: Engagement and Accountability with Psychometric Analysis of a New Instrument, PhD thesis, University of Nevada, Las Vegas

Michaelsen, L.K., Knight, A.B., \& Fink, L.D. (2002). Team-Based Learning: A Transformative use of Small Groups in College Teaching. 1st edition. Westport, Connecticut: Praeger Publishers

Shukr, I., Zainab, R., \& Rana, M.H. (2013) Learning styles of postgraduate and undergraduate medical students. Journal of the College of Physicians and Surgeons Pakistan, 23(1), 25-30. 


\section{Evaluation of inter-professional education activity between third year pharmacy and medical undergraduates}

\author{
K.E. Oates ${ }^{1}$; N. Moteirek ${ }^{1}$; I. Ali ${ }^{1}$; O. Chung ${ }^{1}$, H.A. Juwale ${ }^{2 *}$ \\ ${ }^{1}$ Manchester University NHS Foundation Trust, United Kingdom \\ ${ }^{2}$ University of Manchester, United Kingdom \\ *Corresponding Author: harunjuwale1@manchester.ac.uk
}

Background: Undergraduate pharmacy and medicine programmes must provide opportunities for inter-professional education (IPE) (GMC, 2015; GPhC 2011). This is where two or more professions learn with, from and about each other to improve quality of care (CAIPE 2002). Funding is often a barrier to implementation (Patel et al., 2019).

This IPE used Simulated Patients (SP). In this IPE activity, pharmacy and medicine students worked together to conduct a consultation (medical history, diagnosis and management) using SP, who provided feedback on communication skills.

Aim: To evaluate satisfaction and highlight differences between the pharmacy and medical student experience of SP IPE.

Method: Five-point Likert scale questionnaire was administered to evaluate teaching and perceived improvement in communication or prescribing. Surveys from 2019/20 and 2020/21 were grouped together to increase sample size. Responses were recoded as Agree/Disagree, frequency tables populated, and chi-squared analysis performed.

Results: On assessing confidence levels in communicating with patients, 90.3\% ( $n=65)$ pharmacy students reported greater confidence after teaching, whilst $76.3 \%(n=29)$ medical students described increased confidence $\chi 23.901, p=0.048$.

- 92.1\% ( $n=35$ ) medical students felt more confident prescribing following teaching sessions, compared to a lower percentage of $68.1 \%(n=49)$ of pharmacy students. $\chi 27.970, p=0.005$

- $91.7 \%(n=66)$ pharmacy students and $81.6 \%(n=31)$ medical students felt that the standardised patient feedback could enhance their communication $\chi 22.429, p=0.119$

- $83.3 \%(n=60)$ pharmacy students felt more confident completing a clinical check following the session compared to medical students $57.9 \%(n=22) \times 2$ 8.482, $p=0.004$

Conclusion: SP IPE improved confidence in practice. Pharmacy students stated greater confidence clinically checking prescriptions, medical students stated greater confidence in prescribing. Prescribing is a traditionally medical professional role and clinical checking a pharmacist role. Despite both professions attending the same teaching, reported benefits were in keeping with traditional roles. Due to positive evaluation, funding for SP use in IPE continued.

\section{References}

CAIPE (2002). Defining IPE. Available at: https://www.caipe.org/about-us
GMC [General Medical Council]. (2015). Promoting Excellence: Standards for medical education and training. Available at: https://www.gmcuk.org/-/media/documents/Promoting excellence standards for medical education and training 0715.pdf 61939165.pdf

GPhC [General Pharmaceutical Council]. (2011). Future pharmacists Standards for the initial education and training of pharmacists. Availabe at: https:// www.pharmacyregulation.org/sites/default/files/document/future pharmacists standards for the initial education and training of pharmacists.pdf

Patel, N., Begum, S., \& Kayyali, R. (2016). Interprofessional Education (IPE) and Pharmacy in the UK. A Study on IPE Activities across Different Schools of Pharmacy. Pharmacy (Basel), 4(4), 28. https://doi.org/10.3390/pharmacy4040028

\section{Does using patient as teacher have a positive impact on students' experience?}

A. Lunn*, A. Urmston, S. Seymour, A. Manfrin

University of Central Lancashire, United Kingdom

*Corresponding Author: alunn@uclan.ac.uk

Background: Costello and Horne (2001) suggested that the involvement of patients in a classroom setting makes positive use of their contribution to the teaching and learning of healthcare practitioners. Becket at al. (2014) explained the importance of involving patients in the delivery of pharmacy education. This study is part of a two-year pedagogy research programme to elucidate students' perceptions on the role of patients in the classroom

Aim: To evaluate the impact of the patient as teacher (PAT) on students' experience.

Method: This is an observational study where first and secondyear pharmacy students attended sessions with patients; at the end of each session, students were invited to fill an online questionnaire containing a psychometric scale. The analysis was conducted using SPSS v.26 employing descriptive statistics, Person's chi-square for the goodness of fit, Fisher Exact Test, odds ratio $(O R)$, phi $(\phi)$ to assess the strength of the association between categorical variables. The study received ethics approval (Ref. HEALTH 0029).

Results: Sixty-eight of 228 students participated. No statistical difference was found between gender $(p=0.090)$; a statistically significant difference was found between year $(p=0.008)$. Cronbach's a (0.809) confirmed a good internal consistency. Ninety-seven percent of the students learned a lot, and $85.3 \%$ appreciated and valued the PAT sessions; $89.7 \%$ wanted more sessions; $92.7 \%$ perceived the sessions to contextualise their learning. Five questions were dichotomised into negative and positive; $90.3 \%$ of responses were positive and did not show statistically significant differences in gender and year of study. Overall students' free text comments were positive, however active listening and consultation appeared in the positive and negative domains.

Conclusion: PAT sessions had a positive impact on students' knowledge, communication skills and participation, and contextualised learning. They provide a valuable contribution to the pharmacy students' experience in the United Kingdom. 


\section{References}

Becket, G., Wilson, S.E., Greenwood, K.J., Urmston, A., \& Malihi-Shoja, L. (2014). Involving patients and the public in the delivery of pharmacy education. The Pharmaceutical Journal, 292(7813), 585

Costello, J., \& Horne M. (2001). Patients as teachers? An evaluative study of patients' involvement in classroom teaching. Nurse Education in Practice, 1, 94-102. https://doi.org/10.1054/nepr.2001.0014

Lunn, Andrew M., et al. (2020). Patient as teacher sessions contextualize learning, enhancing knowledge, communication, and participation of pharmacy students in the United Kingdom. Journal of Educational Evaluation for Health Professions, 17(15). https://doi.org/10.3352/jeehp. $\underline{2020.17 .15}$

\section{Baseline study to investigate the ability of Band 5 hospital pharmacy technicians to prioritise patients through identification of medication issues on inpatient medication charts.}

H. Hussain*, N. Lewis

Aston University, Birmingham, United Kingdom

*Corresponding Author: hussah22@aston.ac.uk

Background: Increased National Health Service (NHS) hospitals admissions has increased workload stress within pharmacy department's (Royal Pharmaceutical Society, 2014). Extending the role of hospital pharmacy technicians to prioritise patients for pharmacist review is one possibility to redistribute workload. Training received by technicians is varied and not all are registered with the General Pharmaceutical Council.

Aim: This study investigates the ability of NHS hospital technicians in the West Midlands to recognise inpatient chart issues in order to understand the capability of technicians to prioritise inpatients.

Method: Pharmacy technicians (estimated $n=91$ ), within seven trusts were invited by email to complete an online survey consisting of 15 questions exploring demographical data, Agenda for Change (AfC) band, training received, drug chart format, as well as responses to a mock inpatient medication chart (previously validated in a pilot study in one trust); generating a screening test score.

Results: The survey was sufficiently completed by 31 technicians (estimated response rate 34\%). Average score for the screening test was 21.3/40 (range 1-33). There was no significant difference between those with or without prior completion of a Medicines Management Technician (MMT) course $(t=-1.65)$. The mean score was slightly higher for participants from trusts without electronic prescribing ( $21.8 / 40$ vs $20.3 / 40$ ). Two-way ANOVA results $(p=0.56)$ demonstrated no relationship between AfC band and individual score, however higher scores were seen in those with more experience (average working ten years scoring 27.2/40). Most participants (80.6\%) recognised a serious dosing error with Methotrexate.

Conclusion: Experience is the greatest predictor of ability of technicians to identify medication issues. Training of more experienced staff may enable extension to prioritisation of inpatients for review. A unified approach to technician training would be beneficial. Due to the small sample size, the results may not be representative of the population of hospital technicians in the United Kingdom.

\section{References}

Royal Pharmaceutical Society (2014). Seven Day Services in Hospital Pharmacy; Giving patients the care, they deserve. Available at: https:// www.rpharms.com/Portals/0/RPS\%20document\%20library/Open\%20 access/Professional\%20standards/Professional\%20standards\%20for\%20 Hospital\%20pharmacy/rps-seven-day-report.pdf

\section{Developing student confidence in delivering public health messages}

H. Cook

University of Bradford, United Kingdom

Corresponding Author: h.cook@bradford.ac.uk

Background: The NHS Long Term Plan (NHS, 2019) emphasised the important role pharmacists have in delivering public health $(\mathrm{PH})$ initiatives. From the General Pharmaceutical Council (GPhC) standards for the initial education and training of pharmacists (GPhC, 2011), seven were seen to relate to this role. To develop competence, students need to be given the opportunity to take part in public health initiatives and practice delivering $\mathrm{PH}$ messages.

Aim: To assess whether undertaking community engagement activities in relation to $\mathrm{PH}$ improved student confidence in being able to meet the associated standards (GPhC, 2011).

Method: Stage 2 M.Pharm. students undertook community engagement activities in conjunction with the Council's Department of Health and Wellbeing as part of national Self Care Week. Ethical approval was obtained; a pre- and postcommunity engagement questionnaire consisting of seven 5point Likert scale questions asked students to rate their level of confidence in meeting the GPhC standards that related to delivering $\mathrm{PH}$ messages. Additionally, students were asked to write three words that expressed how they felt about approaching and talking with the public about lifestyle choices. Chi-square test of proportions was used to assess any change in levels of confidence before and after the intervention; free text responses were analysed using an online WordArt generator.

Results: From a sample size of 92 students, 85 (92\%) and 70 (76\%) respectively completed the pre- and post- questionnaires. Table I shows a statistically significant increase $(p<0.05)$ in the level of student confidence for all related standards. The three chosen words to express students' feelings about delivering public health messages pre- and post-intervention stayed largely the same, with the top three being excited, confident and nervous (the latter joint with 'happy' post-intervention).

Conclusion: Community engagement activities can be utilised by pharmacy educators to develop student confidence in delivering $\mathrm{PH}$ messages. 
Table 1: Changes in the level of student confidence

\begin{tabular}{|c|c|c|c|c|c|c|c|c|}
\hline \multirow[b]{2}{*}{ I feel confident that I can: } & \multicolumn{3}{|c|}{ Before $(n=85)$} & \multicolumn{3}{|c|}{ After $(n=70)$} & \multirow[t]{2}{*}{$\mathrm{Chi}^{2}$} & \multirow[t]{2}{*}{$p$} \\
\hline & $\begin{array}{l}\text { SA/A } \\
\%(n)\end{array}$ & $\begin{array}{c}N \\
\%(n)\end{array}$ & $\begin{array}{l}\text { S/SD } \\
\%(n)\end{array}$ & $\begin{array}{l}\text { SA/A } \\
\%(n)\end{array}$ & $\begin{array}{c}N \\
\%(n)\end{array}$ & $\begin{array}{l}S / S D \\
\%(n)\end{array}$ & & \\
\hline $\begin{array}{l}\text { Promote healthy lifestyles } \\
\text { by supporting access to and } \\
\text { understanding of health } \\
\text { promotion information }\end{array}$ & $\begin{array}{c}62.4 \% \\
(53)\end{array}$ & $\begin{array}{c}28.2 \% \\
(24)\end{array}$ & $\begin{array}{c}9.4 \% \\
(8)\end{array}$ & $\begin{array}{c}91.4 \% \\
(64)\end{array}$ & $\begin{array}{c}5.7 \% \\
(4)\end{array}$ & \begin{tabular}{|c|}
$2.9 \%$ \\
$(2)$
\end{tabular} & 17.63 & $<0.01$ \\
\hline $\begin{array}{l}\text { Collaborate with the public } \\
\text { to improve their outcomes }\end{array}$ & $\begin{array}{c}55.3 \% \\
(47)\end{array}$ & \begin{tabular}{|c|}
$35.3 \%$ \\
$(30)$
\end{tabular} & $\begin{array}{c}9.4 \% \\
(8)\end{array}$ & $\begin{array}{l}90 \% \\
(63)\end{array}$ & $\begin{array}{c}10 \% \\
(7)\end{array}$ & 0 & 23.39 & $<0.01$ \\
\hline $\begin{array}{l}\text { Identify a person's desired } \\
\text { health outcomes and } \\
\text { priorities }\end{array}$ & $\begin{array}{c}52.9 \% \\
(45)\end{array}$ & \begin{tabular}{|c|}
$31.8 \%$ \\
$(27)$
\end{tabular} & $\begin{array}{c}15.3 \% \\
(13)\end{array}$ & $\begin{array}{c}87.1 \% \\
(61)\end{array}$ & $\begin{array}{c}11.4 \% \\
(8)\end{array}$ & \begin{tabular}{|c|}
$1.4 \%$ \\
$(1)$
\end{tabular} & 21.77 & $<0.01$ \\
\hline $\begin{array}{l}\text { Communicate information } \\
\text { about available options in a } \\
\text { way which promotes } \\
\text { understanding }\end{array}$ & $\begin{array}{c}63.5 \% \\
(54)\end{array}$ & $\begin{array}{c}27.1 \% \\
(23)\end{array}$ & $\begin{array}{c}9.4 \% \\
(8)\end{array}$ & $\begin{array}{c}78.6 \% \\
(55)\end{array}$ & $\begin{array}{l}20 \% \\
(14)\end{array}$ & \begin{tabular}{|c|}
$1.4 \%$ \\
$(1)$
\end{tabular} & 6.25 & $<0.05$ \\
\hline \begin{tabular}{|l|} 
Support the person in \\
choosing an option by \\
listening and responding to \\
their concerns and \\
respecting their decisions
\end{tabular} & $\begin{array}{c}69.4 \% \\
(59)\end{array}$ & $\begin{array}{c}23.5 \% \\
(20)\end{array}$ & $\begin{array}{c}7.1 \% \\
(6)\end{array}$ & $\begin{array}{c}88.6 \% \\
(62)\end{array}$ & $\begin{array}{c}11.4 \% \\
(8)\end{array}$ & 0 & 9.86 & $<0.01$ \\
\hline $\begin{array}{l}\text { Conclude a consultation to } \\
\text { ensure a satisfactory } \\
\text { outcome }\end{array}$ & $\begin{array}{c}41.2 \% \\
(35)\end{array}$ & \begin{tabular}{|c|}
$43.5 \%$ \\
$(37)$
\end{tabular} & $\begin{array}{c}15.3 \% \\
(13)\end{array}$ & $\begin{array}{c}75.7 \% \\
(53)\end{array}$ & $\begin{array}{c}21.4 \% \\
(15)\end{array}$ & \begin{tabular}{|c|}
$2.9 \%$ \\
$(2)$
\end{tabular} & 19.79 & $<0.01$ \\
\hline $\begin{array}{l}\text { Provide accurate written or } \\
\text { oral information appropriate } \\
\text { to the needs of the } \\
\text { individual }\end{array}$ & $\begin{array}{c}42.4 \% \\
(36)\end{array}$ & $\begin{array}{c}44.7 \% \\
(38)\end{array}$ & $\begin{array}{c}12.9 \% \\
(11)\end{array}$ & $\begin{array}{c}81.4 \% \\
(57)\end{array}$ & $\begin{array}{c}15.7 \% \\
(11)\end{array}$ & $\begin{array}{c}2.9 \% \\
(2)\end{array}$ & 24.63 & $<0.01$ \\
\hline
\end{tabular}

\section{References}

NHS (2019). The NHS long term plan. Available at: https:// www.longtermplan.nhs.uk/

GPhC [General Pharmaceutical Council]. (2011). Future Pharmacists: Standards for the initial education and training of pharmacists. Available at https://www.pharmacyregulation.org/sites/default/files/document/ future pharmacists standards for the initial education and training of pharmacists.pdf

\section{Pharmacy students' professionalism and perceptions in supporting the care of people living with experience of mental health challenges: A feedback- driven qualitative narrative}

\author{
R. Ngomba ${ }^{1 *}$, R. Mosely ${ }^{1}$, J. Solomon ${ }^{1}$, K. Ahmadi ${ }^{2}$ \\ ${ }^{1}$ University of Lincoln, United Kingdom \\ ${ }^{2}$ Universities of Nottingham \& Lincoln, United Kingdom \\ *Corresponding Author: rngomba@lincoln.ac.uk
}

Background: Internalised stigma is considered to be the main barrier to people receiving effective treatment for mental health problems (Knaak et al., 2017). Experiential models of learning complemented with feedback and debriefing are said to be one of the approaches to preparing healthcare professionals who are work ready (Tavares et al., 2019).

Aim: To improve pharmacy students' professionalism in supporting people living with mental health experience via feedback-driven narrative.
Method: Collection of feedback from people living with mental health experiences following an experiential learning activity via interactive learning sessions (ILS) and focus group discussions (FGDs). Manual analysis of the data for themes were used as a guide for a series of semi-structured in-depth interviews with eight people living with mental health experiences and 30 2nd and 3rd year pharmacy students.

Results: Main themes emerged from the FDGs were that people living with mental health experiences want to be seen as a person, not a prescription. Also appreciating that there is no 'magic bullet' to solve all of the challenges. M.Pharm. students felt that the environment for learning was enriching; however, they felt they needed more time to apply their knowledge and skills. When prompted that people with experiences of mental health would want to be looked at as a person and not a prescription; students assimilated the feedback and also recognised that they needed to further integrate their pharmacotherapeutic knowledge.

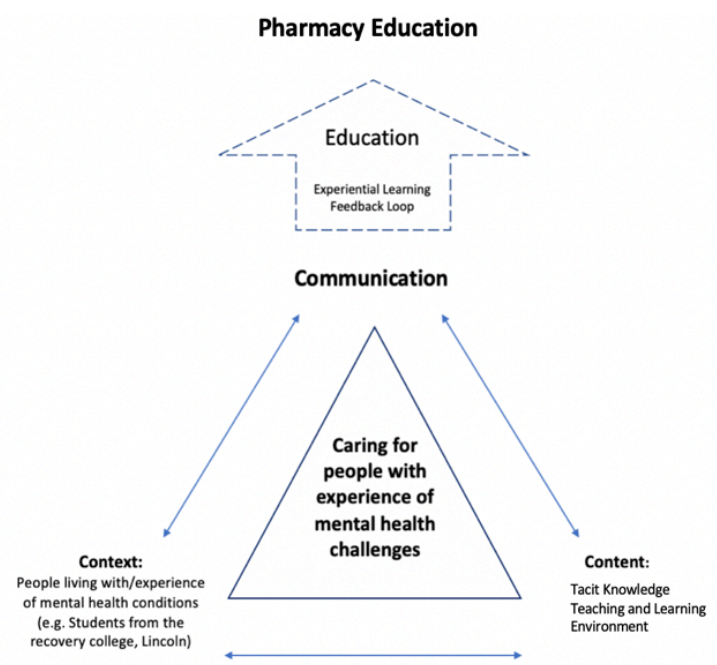

Figure A: Overview of results

Conclusion: The feedback-driven, real-world experiences and experiential learning in the education of pharmacy students, was well-received by M.Pharm. students and appeared to show improvement in their knowledge and professionalism.

In addition to benefiting student's education, it has also allowed for those with mental health experiences to communicate their concerns, as well as enhance their abilities to 'tell their story' more effectively, without fear of stigma or judgement.

\section{References}

Tavares, W., Eppich, W., Cheng, A., Miller, S., Teunissen, P.W., Watling, C.J., \& Sargeant, J. (2020). Learning Conversations: An Analysis of the Theoretical Roots and Their Manifestations of Feedback and Debriefing in Medical Education. Academic Medicine, 95(7), 1020-1025. https://doi.org/ 10.1097/ACM.0000000000002932

Knaak, S., Mantler, E., \& Szeto, A. (2017). Mental illness-related stigma in healthcare. Healthcare Management Forum, 30(2), 111-116. https:// doi.org/10.1177/0840470416679413 


\section{Mental health literacy and help-seeking behaviours in M.Pharm. students}

\author{
N.Ward*, A. Musa \\ De Montfort University, United Kingdom \\ *Corresponding Author: n.ward@dmu.ac.uk
}

Background: A comprehensive understanding of mental health is essential for all healthcare professionals to provide optimal care to those experiencing mental health problems. Unfortunately, patients regularly experience stigmatising attitudes from their care providers, including pharmacists (Rojas-Vistorte et al., 2018). Positive help-seeking behaviours are important to ensure that healthcare professionals seek prompt support and treatment should they experience mental health problems themselves. A good knowledge about mental health is associated with a stronger intention to seek help from their GP (Rusch et al., 2011).

Aim: To determine the level of understanding and perspectives of M.Pharm. students at De Montford University (DMU) regarding mental health issues utilising the Mental Health Literacy Scale (MHLS) (O'Connor \& Casey, 2015) and to explore personal help-seeking behaviours regarding mental health.

Method: An online survey was posted on the VLE for all MPharm students at DMU to access. Questions comprised the MHLS and some additional demographic details.

Results: Ninety-three responses (a 21\% response rate) were obtained (68 female, 24 male, 1 other), with an average MHLS of 123 (range 95-149). There were no statistically significant differences associated with year of study or gender but previous exposure to mental health issues was associated with a higher MHLS (126.57) compared to none (116.88) $(p=0.0012)$. Only $61 \%$ (57) of students were certain that they would seek help from a mental health professional if they had a mental illness. Those that would definitely seek help had a higher MHLS than those that definitely would not.

Conclusion: The most significant contributory factor to an M.Pharm. student's MHLS was their personal exposure to mental health issues, implying the mental health curriculum needs revising to improve awareness of all students. There is some evidence of perceived barriers or reluctance to seek help for personal mental health issues - identifying a need for these stigma to be minimised.

\section{References}

O'Connor, M., \& Casey, L. (2015). The Mental Health Literacy Scale (MHLS): A new scale-based measure of mental health literacy. Psychiatry Research 229, 511-516. https://doi.org/10.1016/i.psychres.2015.05.064

Rojas-Vistorte, A.O., Silva-Ribeiro, W., Jaen, D., Jorge, M.R., Evans-Lacko, S., $\&$ de Jesus, M.J. (2018). Stigmatizing attitudes of primary care professionals towards people with mental disorders: a systematic review. Int J Psychiatry Med., 53(4), 317-38. https://doi.org/10.1177/0091217418778620

Rusch, N., Evans-Lacko, S.E., Henderson, C., Flach., \& Thornicroft, G. (2011) Knowledge and Attitudes as Predictors of Intentions to Seek Help for and Disclose a Mental Illness. Psychiatry Online, 62(6), 675-678. https:// doi.org/10.1176/ps.62.6.pss6206 0675

\section{Exploring M.Pharm. students' perspectives on career paths}

E. Cataag, R. Venables

Keele University, United Kingdom

*Corresponding Author: r.h.venables@keele.ac.uk

Background: The role of a pharmacist is ever changing; this is influenced by the National Health Service (NHS) movements and a drive to make better use of pharmacists within the healthcare system, with respect to their expanding clinical knowledge and skills (Bradley et al., 2018). In the UK, pharmacists' career opportunities are widening and more pharmacists are working outside of the more traditional sectors of pharmacy (e.g. hospital and community). It is important to understand M.Pharm. students' drivers and de-motivators for pursuing a career across different sectors in order to inform M.Pharm. curriculum design.

Aim: To explore the preferred career paths of M.Pharm. students.

Method: A mixed methods questionnaire was designed, informed by the literature and reviewed by the team. Stage 3 \& $4 \mathrm{M}$.Pharm. students were invited to participate. Quantitative data was analysed using chi-square and fisher exact two-tailed tests. Qualitative data was analysed using a thematic analysis approach. Ethics approval was obtained.

Results: Fifty percent (95/191) of M.Pharm. students participated. Most indicated a preference to work in hospital $(43 \%, 41 / 95)$ or community $(29 \%, 27 / 95)$ in the future, followed by GP practice $(21 \%, 20 / 95)$, industrial $(6 \%, 6 / 95)$ and academia pharmacy $(1 \%$, $1 / 95)$. Most agreed that more placement opportunities should be offered within their pharmacy education; 90\% (85/95) believed that these would influence their career decisionmaking; $81 \%(77 / 95)$ of students believed that pharmacists should be more involved in patient care. Also, female students $(75 \%, 48 / 64)$ were significantly more likely to consider doing a postgraduate qualification than male students $(51 \%, 16 / 31)$ $(p=0.045)$.

Conclusion: Study findings suggest that there is interest in newer pharmacy career paths amongst M.Pharm. students; it is important that this informs future degree design in order to ensure pharmacy students gain skills needed to complete newer career roles. A plethora of careers information is provided through our dedicated careers team, yet findings suggest that the provision of further information on the different sectors of pharmacy through placements or cross-sector collaboration opportunities would benefit students when making career decisions.

\section{References}

Bradley, F., Seston, E., Mannall, C., \& Cutts, C. (2018). Evolution of the general practice pharmacist's role in England: a longitudinal study. The British Journal Of General Practice: The Journal Of The Royal College Of General Practitioners, 68(675), e727-e734. https://doi.org/10.3399/ bjgp18X698849 


\section{Academic resilience and well-being of M.Pharm. students}

S.C. Willis ${ }^{1 *}$, C. Langran ${ }^{2}$, L. Hughes ${ }^{3}$, M. Sparks ${ }^{1}$, K. Tsang ${ }^{1}$, S. Shah ${ }^{1}$, A. Barrie ${ }^{1}$, K. Dasani ${ }^{1}$, M. Aboud ${ }^{1}$, H. Zaib ${ }^{1}$, D. Saeed ${ }^{1}$, R. Naji ${ }^{1}$, V. Silkstone ${ }^{1}$, A. Mawdsley ${ }^{1}$, S. Cassidy ${ }^{4}$

${ }^{1}$ University of Manchester, United Kingdom

${ }^{2}$ University of Reading, United Kingdom

${ }^{3}$ Cardiff University, United Kingdom

${ }^{4}$ University of Salford, United Kingdom

*Corresponding Author: sarah.willis@manchester.ac.uk

Background: Academic resilience, the capacity to bounce back from adverse circumstances, is a predictor of student performance, achievement and wellbeing in an educational context (Martin \& Marsh, 2009). With students reporting increasing levels of stress and problems with coping, fostering academic resilience is one possible way to help students develop the psychological resources to be able to bounce back from academic adversity. Yet currently little is known about the academic resilience of undergraduate pharmacy students and its relationship to well-being.

Aim: To investigate M.Pharm. students' academic resilience and well-being

Method: A questionnaire was distributed to all M.Pharm. students based at three schools of pharmacy that included the Academic Resilience Scale (ARS-30) (Cassidy, 2016) and the Warwick Edinburgh Mental Wellbeing Scale (WEMWBS) (Tennant et al., 2007) as well as demographic questions. Descriptive and inferential statistics were used to analyse the data in SPSS v.25.

Results: Response rates varied between $62-79 \%$ at school level, with a total of 1161 students completing the questionnaire. Participants were most likely to be female (71\%) and white (37\%) or Asian (34\%). Academic resilience (AR) varied significantly by school of pharmacy $(p=0.026)$ and year of study with AR declining over the first three years of the M.Pharm. $(p<0.000)$ but did not vary according to participants' demographics. AR and well-being were correlated ( $p<0.000$, medium effect size). AR was found to predict $26 \%$ of variation in participants' well-being.

Conclusion: Given declining AR in the first three years of the M.Pharm., and the association between AR and well-being, ensuring pharmacy students have the psychological resources to bounce back as they progress through their studies needs to be addressed. Future research should focus on determining whether, longitudinally, such differences are important to resilience in practice.

\section{References}

Cassidy, S. (2016). The Academic Resilience Scale (ARS-30): a new multidimensional construct measure. Frontiers in Psychology, 7, 1787. https://doi.org/10.3389/fpsyg.2016.01787

Martin, A.J., \& Marsh, H.W. (2009). Academic resilience and academic buoyancy: Multidimensional and hierarchical conceptual framing of causes, correlates and cognate constructs. Oxford Review of Education 35(3), pp.353-370. https://doi.org/10.1080/03054980902934639
Tennant, R., Hiller, L., Fishwick, R., Platt, S., Joseph, S., Weich, S., Parkinson, J., Secker, J., \& Stewart-Brown, S. (2007). The Warwick-Edinburgh mental well-being scale (WEMWBS): development and UK validation. Health and Quality of life Outcomes, 5(1), 63. https://doi.org/10.1186/1477-7525-5-63

\section{Supporting the foundation pharmacist journey with a teacher practitioner rotation}

A. Oladipo ${ }^{1}$, A. Macadam ${ }^{1}$, A. Conway ${ }^{1,2 *}$

${ }^{1}$ University of Brighton, United Kingdom

${ }^{2}$ Brighton and Sussex University Hospital Trust, United Kingdom

*Corresponding Author: alice.conway@nhs.net

Background: Newly qualified pharmacists traditionally embark on training programmes in multiple fields of practice within secondary care to equip themselves for responsibilities of a registered practitioner.

These programmes vary nationwide yet aim to meet competencies stated in the Royal Pharmaceutical Society (RPS) Foundation Pharmacy Framework (RPS, 2019). Brighton and Sussex University Hospitals (BSUH) Foundation Pharmacist (FP) training programme features a four month innovative teacher practitioner rotation (TPR) established in partnership with the School of Pharmacy and Biomolecular Science University of Brighton (PABS). FPs join an experienced teacher practitioner team to facilitate and supervise undergraduate clinical placements, and undertake the Regional Practice Supervisor (PS) course. We report on the value of this rotation.

Aim: To evaluate:

- Participants views on the TPR benefits and challenges

- How the rotation supports FP skill development

- Student perceptions of placements

Method: This study did not require ethical approval. Semistructured interviews were conducted with FPs who had completed the TPR rotation from August 2016 and February 2019. Data collected were manually coded and thematic analyses used to identify common themes.

Third and fourth year pharmacy students undertaking placements at BSUH between 2018/19 academic year completed the 13 statement questionnaire established by the PABS used to evaluate all placements. Statements were anchored by extreme descriptors four-point Likert scale, (1=definitely agree and 4=definitely disagree).

Results: Of nine eligible FPSs, seven (78\%) undertook semistructured interviews. The four main themes identified were: i) shadowing the current FP undertaking the TPR by the incoming rotational FP was effective rotational preparation; ii) the PS course was perceived as great benefit for the rotation; iii) future development, opportunities for FP clinical skill development via the student tasks were under-utilised; and iv) positive correlation between clinical lecturer role and achievement of RPS 
Foundation Framework attributes including recognises limitations of self and others, organisation, effective clinical skills teamwork and education and training.

One hundred and thirty-six (97\%) of 141 eligible students comprising of 3rd years and 4th years completed the questionnaire and proved an overall positive placement experience with an average response for strongly agree or agree of $90 \%$ for each statement. Statements referring to FP reported above average responses: 'I received adequate direction from the FP (96\%); 'The assigned FP made me feel welcome,' (98.5\%); and 'The placement aided my professional development' (100\%).

Conclusion: Skills developed through this rotation supported the FP progression across the RPS foundation framework. We aim to establish a formal system for ward pharmacists to refer suitable patients to the FPs for student placement tasks that aligns with service provision and further develops clinical learning opportunities for FP and students. FP shadowing of the role prior to commencing the rotation and the PS course are an important contributory factor to the positive experience by the FP. Student evaluation positively informs on the ability of the FP to undertake this role. Study limitations include small participant numbers undertaking the semi structured interviews.

\section{References}

RPS [Royal Pharmaceutical Society]. (2019). Foundation Pharmacy Framework. Available at: https://www.rpharms.com/resources/ frameworks/foundation-pharmacy-framework-fpf

\section{Evaluating the design and implementation of an authentic assessment in M.Pharm. students}

R. Venables*, K.H. Thakrar, K. Maddock

Keele University, United Kingdom

*Corresponding Author: r.h.venables@keele.ac.uk

Background: Graduating pharmacy professionals should be competent and confident in completing tasks (in the stimulated environment), in preparation for their pre-registration training year as per General Pharmaceutical Council (GPhC, 2011). Although it is not expected that they will be completing such tasks autonomously upon graduation, the final assessment before the workplace should be as realistic as possible. Using Miller's competency pyramid (Wass et al., 2001), some tasks should be at the 'shows how' or 'does' levels. These can be achieved using authentic assessments, supported by Mueller (2006) who theorises that assessments should require students 'to perform meaningful tasks that replicate real world challenges'. An authentic assessment was designed and implemented, with students as co-designers at various stages. Short audio recordings of answers to real-life cases replace a written theoretical paper.

Aim: To investigate student and staff perspectives' regarding a new authentic assessment for M.Pharm. students.
Method: The mock and main assessments were evaluated using an online mixed-methods questionnaire. This was adapted for tutors and students accordingly. Thematic analysis was used. Ethics approval was obtained.

Results: The total number of participants were $52 \%$ (56/108) of M.Pharm. students and five tutors for the mock and $49 \%$ $(53 / 108)$ of M.Pharm. students and five tutors for the main assessment. The assessment evaluated mostly positively; forming recommendations regarding student confidence, key skillset developments, team-work and groupings, and case design. Findings suggest that staff also developed various skills.

Conclusion: This authentic assessment has shown increasingly positive staff and student evaluation. Students' perceived they had developed skills throughout this assessment. The assessment meets course intended learning outcomes, professional regulations and HEA practices, and is strongly underpinned by pedagogy. Findings are transferrable to other disciplines and of particular interest to educators aiming to improve the authenticity of teaching and assessments and thus skill development and the quality of graduates.

\section{References}

GPhC [General Pharmaceutical Council]. (2011). Future pharmacists: Standards for the initial education and training of pharmacists. Available at: https://www.pharmacyregulation.org/sites/default/files/document/ future pharmacists standards for the initial education and training of pharmacists.pdf

Mueller, J. (2006). Authentic assessment toolbox: What is authentic assessment? Available at: http://ifmueller.faculty.noctrl.edu/toolbox/ whatisit.htm

Wass, V., Van der Vleuten, C., Shatzer, J., \& Jones, R. (2001). Assessment of clinical competence. The Lancet, 357(9260), 945-949. https://doi.org/ $\underline{10.1016 / 50140-6736(00) 04221-5}$

\section{Evaluating M.Pharm. Stage 3 students' use and preference of electronic modules versus e-books for their learning}

\author{
R. Venables \\ Keele University, United Kingdom \\ Corresponding Author: r.h.venables@keele.ac.uk
}

Background: To optimise success of a teaching innovation, positive digital learning and teaching need to be attained (JISC, 2020a). It is known that students have different styles of learning (VARK, 2018). Some students may prefer more 'traditional styles' of learning; anecdotal data suggests that some students prefer to use electronic documents in a non-digital format. Developing students' skills when using new technologies is key with regard to future employability; students require a wide skill set, including digital skills (JISC, 2020b) in a competitive market.

Aim: To evaluate M.Pharm. Stage 3 students' use and preference of electronic modules versus e-books for their learning. 
Method: The study used a short mixed-methods online questionnaire, informed by pedagogical literature in the field. This was emailed to all Stage 3 students. Thematic analysis was used to analyse qualitative data and descriptive statistics were also reported. Ethics approval was obtained.

Results: Fifty-nine M.Pharm. Stage 3 students participated. Ebooks were rated better (based on likert scale-type questions) than online modules with respect to: supporting and enriching learning and revision, ease of navigation and overall preference when studying. Students reported a strong preference for paper versions of both e-books (78\%) and online modules (57\%). A common theme for improvement was having a printable format; mostly to enable annotation. Fourty-one percent of respondents disagreed/strongly disagreed that online modules support their overall learning for a specific therapeutic area, whilst only one respondent felt this way about e-books.

Conclusion: Study findings suggest that students prefer e-books to online modules, specifically utilising paper versions of e-books, to enable annotations to be added. Future work adopting a co-productive approach utilising focus groups to explore this further would be beneficial to explore this in more depth. It is important that educators balance learning methods to encourage students with different learning needs and preferences, to optimise inclusive, blended learning.

\section{References}

JISC (2020a). Building digital capabilities: The six elements defined. Available at:https://repository.jisc.ac.uk/6611/1/JFL0066F DIGIGAP MOD IND FRAME.PDF

JISC. (2020b). Designing learning and assessment in a digital age. Available at: https://www.jisc.ac.uk/guides/designing-learning-and-assessment-in-adigital-age

VARK. (2018). VARK learn limited: a guide to learning styles. Available at: http://vark-learn.com/introduction-to-vark/ 